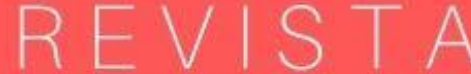 AUGUSTUS
}

\section{MY MAD FAT DIARY: UMA ANÁLISE PSICANALÍTICA DA AUTOMUTILAÇÃO NA ADOLESCÊNCIA}

\author{
Rafaelli Fargnoli Nascimento \\ Pós-graduada em Psicologia e Saúde Mental pela Faculdade Metropolitana do Estado de São \\ Paulo (FAMEESP), São Paulo, SP, Brasil \\ rafaellifargnoli@gmail.com \\ Thalita Lacerda Nobre \\ Pós-doutoranda em Psicologia clínica pela Pontifícia Universidade Católica de São Paulo \\ (PUC-SP), São Paulo, SP, Brasil \\ thalitaln@gmail.com
}

\section{RESUMO}

São cada vez mais frequentes relatos sobre a automutilação em escolas, clínicas de saúde e nas redes sociais, que impulsionam o aumento de informação sobre esta prática, promovendo questionamentos sobre os significados e a influência deste ato na vida das pessoas, principalmente quando nos referimos a adolescência, que é um período de grandes transformações, dentre elas, a construção de identidade. $O$ ato de se automutilar significa machucar o próprio corpo de uma forma voluntária, sem a intenção do suicídio, tendo como intuito amenizar o sofrimento vivenciado. Tomando como base a frequência desta prática, surge uma necessidade de definir e pesquisar a respeito do contexto histórico, os aspectos psicodinâmicos e sociais envolvidos na automutilação de adolescentes. Para uma maior articulação sobre a temática, foi utilizada a série televisiva britânica My Mad Fat Diary (2013), enfocando precisamente a personagem Rachel como uma forma ilustrada de discussão de um possível caso clínico. Pode-se dizer que a automutilação no caso da personagem surge com o intuito de descarregar os impulsos destrutivos e libidinais da jovem, que sente alívio por meio da dor em seu corpo.

Palavras-chave: Automutilação. Adolescência. Psicanálise. My mad fat diary.

\section{MY MAD FAT DIARY: A PSYCHOANALYTICAL ANALYSIS OF SELF-MUTILATION IN ADOLESCENCE}

\begin{abstract}
There are more and more frequent reports about self-mutilation in schools, health clinics and social networks, which boost the increase in information about this practice, promoting questions about the meanings and the influence of this act in people's lives, especially when we refer to adolescence, which is a period of great transformations, among them, the construction of identity. The act of self-harm means hurting one's own body on a voluntary basis, without the intention of suicide, with the aim of alleviating the suffering experienced. Based on the frequency of this practice, there is a need to define and research about the historical context, the psychodynamic and social aspects involved in the self-mutilation of adolescents. For a greater articulation on the subject, the British television series "My Mad
\end{abstract}


Fat Diary" (2013) was used, focusing precisely on the character Rachel as an illustrated way of discussing a possible clinical case. It can be said that self-mutilation in the case of the character arises in order to discharge the destructive and libidinal impulses of the young woman, who feels relief through the pain in her body.

Keywords: Self-mutilation. Adolescence. Psychoanalysis. My mad fat diary.

Recebido em: 31/10/2020. Aceito em: 03/02/2021. 


\section{INTRODUÇÃO}

De acordo com uma pesquisa realizada pelo jornal britânico (CAMPBELL, 2016), o índice de crianças e adolescentes que cometem automutilação tem crescido drasticamente no Reino Unido nos últimos 10 anos. O número de jovens menores de 18 anos admitidos em hospitais após se cortarem, envenenarem-se ou tentarem suicídio é maior em meninas, porém, tem aumentado cada vez mais em meninos também (CAMPBELL, 2016). O mesmo jornal, em 2017, revelou que casos de automutilação em meninas adolescentes com menos de 17 anos sofreram uma elevação de 68\%, em comparação com três anos anteriores (DAVIS, 2017).

No Brasil não há estatísticas oficiais sobre a automutilação. Manual produzido pelo Ministério da Mulher, da Família e dos Direitos Humanos, intitulado "O suicídio e automutilação tratados sob a perspectiva da família e do sentido da vida", oferece dados relacionados à execução e tentativa de suicídio, porém, não relacionados à automutilação (BRASIL, 2019b).

A presente pesquisa fundamenta-se numa abordagem qualitativa, pois se trata de um estudo documental. O estudo documental é desenvolvido com base em material que ainda não recebeu um tratamento, analítico. Os dados de pesquisa foram coletados nos sites acadêmicos Scielo, Pepsic, Google Acadêmico, reportagens de jornais, sites de interação, de uma série televisiva e de livros.

A pesquisa foi dividida em três itens, sendo que no primeiro foi discutido a questão da adolescência; no segundo foi abordado a automutilação e no terceiro, para agregar um maior conhecimento prático na pesquisa, foi desenvolvida uma discussão e integração do tema escolhido, com a série britânica de 2013, "My Mad Fat Diary", que servirá como um estudo de caso advindo de uma produção artística.

\section{ADOLESCÊNCIA}

O período da adolescência refere-se a um dos estágios de desenvolvimento dos seres humanos, que segundo o Estatuto da Criança e do Adolescente (ECA) no artigo 2a da Lei no 8.069, de 13 de julho de 1990, considera adolescente o indivíduo com idade entre doze e dezoito anos (BRASIL, 1990). Segundo a Organização Mundial da Saúde (OMS) (ORGANIZAÇÃO 
MUNDIAL DE SAÚDE, 2008), a idade cronológica que demarca a adolescência está entre 10 e dezenove anos. Marcado por diversas alterações físicas, psicológicas e de relacionamento social que modificam as perspectivas do jovem sobre si, é um estágio de maturação, que tem como função direcionar a transição da passagem da infância para a vida adulta.

De acordo com Aberastury e Knobel (1992), a adolescência é um período em que ser independente, mas ao mesmo tempo, dependente é algo extremamente desejado. Pode ser considerado como um momento de transição e confusões, carregado de ambivalência de sentimentos, que surgem a partir de dolorosas interações com o meio social e familiar. Este período de mudança, segundo os autores, implica uma busca por uma nova identidade, no qual o adolescente se encontra em conflito por perder sua identidade como criança, buscando assim construir uma nova a partir de seu consciente e inconsciente, sendo que nesse período ele oscila em não desejar ser visto como um adulto, porém busca se identificar com sujeitos dessa fase, construindo assim de uma forma lenta sua identidade.

\subsection{Aspectos do desenvolvimento psicossocial da adolescência}

Para Calligaris (2000), o adolescente pode ser definido como alguém que possui o tempo para assimilar os valores e necessidades expressados pela comunidade, um sujeito que sofreu com a maturação de seu corpo, estando suficientemente desenvolvido biologicamente para consagrar estas tarefas idealizadas pelos valores e cultura em que está inserido, porém, conforme Erikson (1976) considera o sujeito adolescente vive um período em que é necessário que decrete "moratória social", com um tempo necessário a se desenvolver.

A respeito da moratória, Veríssimo (2002) comenta que durante a transição entre infância e juventude, o sujeito vive um período de crise. Isso porque está longe de ser um adulto, porém, por conta das mudanças fisiológicas e biológicas que sofre, ele também não consegue mais se identificar com seu corpo infantil. Por essa razão, o pedido inconsciente de moratória se faria necessário.

Conforme escreve Calligaris (2000), o sujeito só é reconhecido como adolescente, quando possui a capacidade de ser treinado e moldado por vários agentes sociais como a escola, família, mídia, que buscam com que o indivíduo internalize a ideologia da sociedade, que busca preparar o mesmo para o sexo, o amor e o trabalho. 
A adolescência, segundo o que escreve Levisky (1995) refere-se a um momento único do desenvolvimento do sujeito, que experiencia um segundo nascimento durante esse período, já que é como adolescente que o homem se redefine como sujeito, consolidando sua identidade básica.

Levisky (1995) também evidencia que a forma como a transição de uma identidade infantil para uma identidade adulta será vivenciada durante a adolescência dependerá de suas vivências infantis, além de suas relações sociais e de afeto. A forma como o adolescente vivenciou seu conflito edipiano também irá influenciar na construção de sua subjetividade. Nessa fase, também, ocorre uma desorganização do ego e do superego, que acabam gerando inúmeros conflitos devido a busca do adolescente por uma identidade adulta que englobe aspectos cognitivos, sociais e sexuais.

\subsubsection{A puberdade na adolescência}

A puberdade, de acordo com o que escreve Palacios (1995), refere-se a todas as mudanças físicas que ocorrem no corpo do adolescente, preparando o mesmo para a reprodução, ou seja, alterando o corpo de criança para o de adulto. Segundo Lourenço e Queiroz (2010), este período não é similar a adolescência, mas está inserido na mesma, uma vez que a puberdade se refere às mudanças físicas e a adolescência à consideração psicossocial desse período.

Estas transformações físicas, segundo os autores, tornam-se gritantemente diferentes nos corpos femininos e masculinos. Levisky (1995) escreve que essas mudanças corporais são iniciadas com o aparecimento de pelos pubianos e axilares, o aumento da força muscular, a alteração na voz, a distribuição de gordura, o desenvolvimento dos seios (meninas) e do pênis e testículos (meninos), as primeiras ejaculações, a menstruação (meninas) e por fim, a masturbação. $O$ autor também coloca que esse processo de alteração biológica ocasiona mudanças na personalidade e na identidade do adolescente, mesmo que nos tempos iniciais, elas não sejam perceptíveis no comportamento dele. Ele passa a se sentir estranho, não conseguindo entender o que está acontecendo consigo e porque se sente tão diferente do que era antes, seja por meio de seus novos impulsos agressivos ou a partir de seu novo interesse pela sexualidade. Levisky (1995), evidencia que o adolescente pode vir a querer 
esconder as mudanças corporais que está sofrendo, negando a si mesmo suas novas características físicas.

\subsubsection{A imagem corporal e sua relação com o adolescente}

Conforme abordado anteriormente, as transformações corporais possuem extrema importância na adolescência, já que é a partir do corpo que o adolescente se expressa para o mundo. Levisky (1995), escreve que a imagem corporal que o adolescente possui de si mesmo, vai sendo alterada à medida que as mudanças físicas vão acontecendo.

Durante a adolescência, segundo Levisky (1995), a insatisfação corporal e a sensação de desproporcionalidade são bastante comuns, fazendo com que o adolescente se sinta estranho em relação ao próprio corpo e imagem que possui de si mesmo. O autor evidencia que a imagem corporal, além de ser subjetiva, é influenciada por vários aspectos, como: social, emocional e funcional.

Conforme escrevem Esslinger e Kovács (1998), essas modificações geram grande preocupação, por parte do adolescente, com seu próprio corpo, que a princípio, se torna algo estranho para ele. Portanto, para as autoras é natural que os jovens busquem se olhar no espelho e a reparar nos outros com frequência. Todas estas mudanças, como tamanho dos seios, altura, pés, nariz e a quantidade de espinhas, por exemplo, sofrem com esse processo comparativo.

Esta idealização sobre a imagem corporal pode levar o adolescente a reagir com ansiedade e frustração, contribuindo para que ele se sinta, segundo o autor, desvalorizado. Este quadro pode vir a evoluir também para um quadro de depressão, fazendo com que o jovem se sinta rejeitado e rejeite a si próprio, já que se enxerga na maioria das vezes como fora dos padrões e se sente insatisfeito com sua forma física.

A partir destas transformações o adolescente passa a se aproximar cada vez mais, de acordo com Levisky (1995), de sua forma adulta. Durante este processo, o autor coloca que o jovem passa a incorporar as suas mudanças, se apropriando assim de seus sentimentos, que acabam por repercutir em sua personalidade, principalmente quando se fala em suas figuras de identificação. 


\subsection{Narcisismo, o processo de identificação e o ideal do ego na adolescência}

De acordo com Freud (1996d), o narcisismo é o sistema que organizará o ego do sujeito, que sofre com investimentos libidinais. O ego para o autor, possui como função a regularização e a proteção da realidade do sujeito.

O processo narcísico também pode ser caracterizado da seguinte forma, conforme o que evidencia Freud (1996b), como um momento em que os impulsos libidinais trabalham na busca pelo prazer, sem procurar preocupar-se com as necessidades dos demais, focando assim na satisfação de seus próprios impulsos. Por meio do narcisismo ocorre a eleição do objeto libidinal.

Segundo Levisky (1995), o narcisismo é um movimento em evidência durante a adolescência, sendo responsável pela manutenção da autoestima no sujeito, participando assim do processo de estruturação da identidade e de suas identificações. Ainda, de acordo com o autor, é de extrema importância que o adolescente mantenha sua autoestima elevada, o que pode vir a ser um caminho difícil, já que o indivíduo se encontra em um estado de fragilidade no ego, o que gera situações em que esta autoconfiança possa vir a ser abalada.

O processo de identificação é algo complexo e ativo, segundo o que expressa Levisky (1995), ele tem início na relação com os pais, que direcionam aos filhos seus narcisismos, conforme postulado por Freud (1996d).

Segundo Levisky (1995), os processos de identificação causam mudanças na estrutura psíquica interna do sujeito, afetando assim o ego e o superego dele. $\mathrm{O}$ autor evidencia que esse mecanismo é iniciado a partir da imitação, sendo transformado posteriormente na identificação. Levisky (1995) evidencia que o resultado da identificação seria a formação da identidade, que sofre consequências a partir das mudanças experienciadas.

Para o autor, os mecanismos de identificação na adolescência surgem a partir do relacionamento existente entre o adolescente e seus pais, que servem como modelos para seus filhos, que incorporam aspectos de suas figuras parentais. É importante evidenciar que neste processo a cultura também se faz presente, já que impõe seus valores.

A partir do ser biológico, Levisky (1995) evidencia a descoberta de novas possibilidades a serem desenvolvidas pelas pulsões, que buscam se encontrar com seus objetos de identificação, que possuem o caráter de beneficiar os desejos libidinais e primitivos do adolescente, que a partir disso, desenvolve sua identidade adulta. Segundo o autor, para 
chegar a este nível, o sujeito passa por um complexo e conturbado processo de reestruturação do ego.

Esta crise de identidade ocorre de forma ambígua, de acordo com o que escreve Levisky (1995), já que o adolescente possui desejos que o impulsionam a se tornar adulto, mas ao mesmo tempo, não querem abdicar de sua vida infantil, já que nesse período o mesmo acaba por vivenciar certos ganhos que não são comuns durante a adolescência. O jovem neste período anseia se tornar adulto e ao mesmo tempo teme adquirir as responsabilidades de um mesmo.

Quando se é referido a expressão de Ideal do Ego, descrita por Freud em sua segunda teoria do aparelho psíquico, é possível evidenciar que: “É uma instância da personalidade resultante da convergência do narcisismo (idealização do ego) e das identificações com os pais, com seus substitutos e com os ideais coletivos." (LAPLANCHE; PONTALIS, 2001, p. 222).

Esse conceito para Zimerman (2001), é baseado na forma que o indivíduo se torna suscetível às aspirações dos outros, em relação de quem ele deve ser e o que tem que ter. Esse processo pode vir a gerar um sentimento de vergonha, quando a pessoa não consegue atingir as expectativas impostas por terceiros. Em relação ao adolescente, isso pode ser visualizado na forma como ele se identifica com suas figuras parentais e com suas figuras externas, como os grupos que escolhe fazer parte.

Segundo Levisky (1995), o jovem adolescente vivencia uma situação de terror e angústia durante essa fase de sua vida, em que ele entra em contato com seus conflitos gerados pela sua vivencia do complexo de Édipo, que irá determinar uma maior aceitação de sua nova identidade sexual, tornando-se assim mais aptos para manterem relacionamentos saudáveis. Esse autor também evidencia que durante esse período da adolescência, o ego se mostra insuficiente para conter os impulsos agressivos e sexuais dos jovens, podendo fazer uso, em maior intensidade, de mecanismos de defesa como forma de controle.

\subsection{A síndrome da normalidade no adolescente}

A "síndrome da adolescência normal" foi um conceito desenvolvido pelos autores Aberastury e Knobel (1992), que sintetizaram as características de adolescentes da seguinte forma: a busca por si mesmo e da identidade; a tendência grupal; a necessidade de fantasiar e intelectualizar; as crises religiosas; a evolução sexual; a deslocação temporal; atitude social 
reivindicatória; contradições sucessivas em todas as manifestações de conduta; separação progressiva dos pais e constantes alterações no humor e no estado de ânimo.

\section{O FENÔMENO DA AUTOMUTILAÇÃO}

A automutilação pode ser definida, de acordo com os Descritores em Ciência da Saúde (CENTRO LATINO-AMERICANO E DO CARIBE DE INFORMAÇÃO EM CIÊNCIAS DA SAÚDE, 2015), como o ato de lesionar o próprio corpo, podendo destruir um membro ou outra parte corporal de forma permanente. Nessa biblioteca virtual, é possível encontrar também uma relação dessa temática com o termo comportamento autodestrutivo, que significa o ato de machucar ou fazer mal a si mesmo sem que o sujeito deseje ou tenha a intenção de se suicidar ou realizar alguma perversão sexual.

Favazza (1996), definiu na obra Bodies under siege a automutilação como a prática que visa deliberadamente destruir ou alterar uma parte do corpo, sem a existência de uma intenção suicida.

Favazza (1996), divide o comportamento automutilatório em dois grupos: o primeiro corresponde à automutilação cultural, que inclui rituais e práticas sancionadas a partir de uma determinada cultura. O segundo grupo refere-se à automutilação desviante, no qual a prática, normalmente, possui relação com transtornos mentais ou angústias. As práticas de automutilação presentes na segunda categoria podem ser divididas em três subgrupos: grave, estereotipada ou moderada/superficial. Para o autor, a automutilação grave corresponde à episódios relacionados à castração ou à amputação. Associam-se à surtos psicóticos graves estando ou não o sujeito sob efeito de substâncias psicoativas.

Para Favazza (1996), a automutilação estereotipada, refere-se à prática de comportamentos repetitivos, como bater a cabeça várias vezes ou o ato de se arranhar. A automutilação superficial ou moderada pode ser definida a partir da prática de machucar a pele de maneira leve ou profunda, normalmente utilizando objetos cortantes e pontiagudos. Essa forma de automutilação pode ser dividida em três partes: compulsiva, episódica e repetitiva. A diferença entre elas irá depender do sentido e a frequência destes atos na vida do sujeito. 
Favazza (1996) também observou que muitas das pessoas que praticam automutilação normalmente não sentem dor ou arrependimentos após o ato, pelo contrário, relatam, geralmente, uma sensação de alívio.

Ainda sobre o fenômeno da automutilação, é importante destacar a influência da mídia nessa prática, que está ligada com a forma como a internet, redes sociais e blogs a disseminam. É cada vez mais comum encontrar relatos de jovens automutiladores nas redes sociais, principalmente em postagens voltadas para a prática automutilatória, contendo imagens dos cortes e frases reflexivas sobre este ato, que passa a se tornar um fenômeno exibicionista e não mais secreto, já que na internet os jovens se vinculam com outros adolescentes que se automutilam da mesma maneira que eles, promovendo assim um sentimento de acolhimento.

Segundo Venosa (2015), é possível evidenciar os motivos que levam o assunto automutilação a não ser discutido ou divulgado pela mídia seriam a incidência dessa prática e o medo do contágio, ou seja, da possível influência que a obtenção de informação possa vir a gerar. Uma questão importante que a autora evidencia é a falta de divulgação em reportagens sobre o que se fazer em casos emergenciais, sendo comum apenas a indicação de profissionais e não os serviços referenciais ou locais em que estas pessoas atuam. Com isso, as informações se tornam ineficientes, motivando a curiosidade sobre a temática e não promovendo o conhecimento adequado sobre ela.

Em relação a políticas preventivas contra a prática de automutilação, o governo brasileiro, no primeiro semestre de 2019 , sancionou a Lei no $13.819 / 2019$, que institui a Política Nacional de Prevenção da Automutilação e do Suicídio no Brasil (PNPAS). Esta constitui um marco legal para possíveis regulamentações (decretos, portarias) que possam ser implementadas no território nacional, a fim de prevenir o suicídio e a automutilação (BRASIL, 2019a).

Esta nova legislação surge com o objetivo de expor para a população a autolesão e o suicídio como problemas de saúde pública, promovendo, assim, a saúde mental e a sensibilização em relação a essas problemáticas. 


\subsection{Automutilação sob a perspectiva psicanalítica.}

Acerca da automutilação, Araújo et al. (2016) destacam que um dos primeiros estudiosos a abordar essa temática foi o psicanalista e psiquiatra Karl Menninger, que estudou este fenômeno a partir de um ponto de vista psicanalítico, publicando o livro: "Eros e Tanatos: o homem contra si próprio", em 1934.

A partir da teoria de Menninger, Strong (2009) destaca que a agressão pode ser voltada para o interior do indivíduo e pode esse movimento ser representante do par amoródio vivenciado em relação aos pais. Também, a agressão pode ser desencadeada a partir de uma intenção sexual e, como um terceiro movimento possível, há a possibilidade de a agressão desempenhar uma função de autopunição, o que estaria relacionado à busca pela expiação de um "pecado" vivido pelo psiquismo do sujeito.

Dessa forma, o ato de se automutilar surge como uma alternativa do sujeito não se aniquilar totalmente, gerando um suicídio. Isto pode ser associado com a psicanálise no sentido desta aniquilação, apenas parcial, poder ser considerada como uma luta entre a pulsão de morte e a de vida, que neste caso, a segunda pode se considerar como vitoriosa.

Freud (1996a), em "Uma criança é espancada - uma contribuição ao estudo da origem das perversões sexuais", postulou que a fantasia de espancamento existente na infância, surge de maneira primitiva, tendo como objetivo a satisfação autoerótica, que pode ser classificada como uma forma de perversão, a princípio. O autor evidencia que tais fantasias infantis podem vir a serem reprimidas ou sublimadas, porém, caso estes processos não ocorram, esta perversão pode ser carregada até a vida adulta, gerando assim gostos sexuais, como o fetichismo, por exemplo. Estas fantasias se mantêm inconscientes, possuindo grandes significados para o sujeito, que passa a obter seu prazer por meio delas.

Nesse texto, Freud (1996a), expõe que estas fantasias de espancamento estão relacionadas com suas figuras parentais. Esta perversão passa a não ser mais um fator isolado da vida sexual da criança, mas sim se torna a relação entre o relacionamento incestuoso dela, que escolhe como objeto de amor seu pai ou sua mãe.

Quando se refere a forma como o masoquismo se apresenta, o autor aborda três representações: "Uma condição imposta à excitação sexual, como expressão da natureza feminina e como forma de comportamento. Podemos, por conseguinte, distinguir um 
masoquismo erógeno, um masoquismo feminino e um masoquismo moral" (FREUD, 1996c, p. 2).

A primeira definição, o masoquismo erógeno, que pode ser evidenciado como a forma de se sentir prazer por meio da dor, para Freud (1996c), permanece inexplicável, a não ser que assuntos obscuros passem a ser abordados e aprofundados. Esta forma de masoquismo pode ser comparada, a partir de uma possível hipótese, com o fenômeno da automutilação, no qual o sujeito praticante sente excitação ao machucar a si mesmo, gerando assim um alívio de seu sofrimento por meio da dor.

O masoquismo moral, conforme o que escreve Freud (1996c), pode ser descrito como uma forma de culpa inconsciente manifestada no sujeito. Nesta forma, o sofrimento é o fator mais importante. O autor evidencia que o masoquista está sempre disposto a oferecer a si mesmo para apanhar, sendo que o instinto destrutivo:

[...] se volta novamente para dentro e agora se enfurece contra o eu (self), contudo, deve haver algum significado no fato de o uso linguístico não ter abandonado a vinculação entre essa forma de conduta e o erotismo, e chamar também de masoquistas esses ofensores de si próprios (FREUD, 1996c, p. 6).

Este masoquismo moral possui relação direta com a pulsão de morte, pois segundo Zimerman (2001), o sujeito acaba por se autoflingir, gerando dores para si, que carregam uma grande culpabilização e uma necessidade inconsciente de ser castigado. Esta reflexão do autor também pode ser comparada, conforme uma possível hipótese, com a automutilação, devido ao fato do sofrimento e dor ser direcionado a ele mesmo.

\section{PROCESSO DE AUTOMUTILAÇÃO NA ADOLESCÊNCIA E SUAS POSSÍVEIS ARTICULAÇÕES}

O fenômeno da automutilação na adolescência, conforme evidenciado no decorrer deste trabalho, pode estar relacionado com vários fatores, como por exemplo a depressão, quadros obsessivos, ansiedade, relacionamentos familiares e outros. A fim de ampliar a discussão, foi analisado neste capítulo, como exemplificação de um caso clínico, a personagem Rachel, da série televisão britânica My Mad Fat Diary. Tal série aborda questões que vão além da prática de automutilação, porém, acabam por estarem entrelaçadas com ela, como a busca por autodestruição, a obesidade, a compulsão alimentar, a descoberta da homossexualidade, entre outros transtornos. 


\subsection{Análise do caso de Rachel, personagem da série “My Mad Fat Diary”}

A série britânica "My Mad Fat Diary", traduzida livremente em português como "Meu diário louco e gordo", aborda a história de Rachel Earl, apelidada de "Rae", uma adolescente de 16 anos, obesa e que acaba de deixar um hospital psiquiátrico, onde esteve internada por quatro meses, após tentar tirar sua própria vida em seu quarto, quando se encontrava sozinha. Este seriado televisivo é vivenciado nos anos 90 , em uma pequena cidade inglesa chamada Lincolnshire.

A personagem Rachel, ou Rae, é uma adolescente que possui diagnósticos de compulsão alimentar, ansiedade e práticas de automutilação. A jovem também possui em seu histórico clínico duas tentativas de suicídio, sendo a primeira responsável por gerar uma internação em uma clínica psiquiátrica, a qual permaneceu durante quatro meses em tratamento.

A adolescente é obesa, amante de música e apaixonada por garotos, apesar de não acreditar que possa se relacionar com um por conta de sua aparência. É extrovertida e leal às pessoas, buscando satisfazer as necessidades dos outros em primeiro lugar.

A jovem foi criada por sua mãe, sendo que seu pai deixou a família enquanto ela ainda era criança. Possui um relacionamento de amor e ódio com sua mãe, pois ao mesmo tempo que é grata por sua figura materna estar sempre presente, acredita que ela é irresponsável e que não consegue compreender o que ela sente ou vivencia. A questão de seu pai tê-la abandonado quando criança, possivelmente a fez construir um forte sentimento de rejeição. Ela acreditava que seu pai havia ido embora por causa dela.

Nesse ponto, podemos interpretar, a partir do que fora discutido anteriormente sobre o narcisismo que a personagem poderia ter vivido, com o abandono do pai, uma ruptura significativa em seu narcisismo, identificando-se com a perda que não fora podido ser sanada na relação com a mãe. Essa compreensão de culpa pela ausência do pai e fragilidade da mãe levou Rachel ao esvaziamento da autoestima e à alimentação do masoquismo.

Rae apresenta um grande rebaixamento de autoestima, que faz com que ela não aceite a si mesma e localize suas frustrações em seu corpo. Pode-se analisar que o corpo visto pela menina, no espelho, é um corpo inadequado, que merece ser desvalorizado, sentimento análogo ao que acreditou merecer receber dos pais. 
Essa dificuldade de aceitação acarreta grandes problemas para a jovem, que possui dificuldades para se relacionar com os outros, aumentando seu sentimento de incapacidade e de nunca ser boa o bastante para as pessoas, a imagem distorcida pela desvalorização de si também era direcionada às pessoas em forma de supervalorização do outro. A autocobrança e rejeição de si provoca uma grande angústia na adolescente, que passa atribuir para si comportamentos autodestrutivos como forma de aliviar seu sofrimento, sendo eles o comer compulsivamente e se automutilar.

Durante a série é possível visualizar que a jovem pratica vários atos de automutilação, como cortar suas pernas, queimar suas costas durante o banho com a água quente e machucar suas mãos ao socar a parede de forma repetitiva durante algumas de suas crises, tentando infligir ao corpo desajustado uma possível punição.

Ela apresenta, também, o comportamento de não conseguir comer na frente das pessoas, demonstrando receio do que os outros possam pensar acerca de suas escolhas alimentares, desenvolvendo o raciocínio de que se comer demais estará sendo vista como alguém que é gorda por este hábito e se comer de menos será uma pessoa que é gorda, porém está tentando emagrecer. Tal lógica pode ser analisada como uma tentativa, sempre frustrada, do desejo de se ajustar em torno dos prazeres vivenciados pelo corpo. $\mathrm{O}$ ato de se alimentar na frente das pessoas, possui, de acordo com uma interpretação de base freudiana, um caráter duplamente erótico, uma vez que se satisfaz a pulsão alimentar por uma espécie de via exibicionista ao outro que vê. De acordo com o que fora discutido no item anterior, sobre a adolescência, é possível correlacionar que tal comportamento de vergonha em relação à sexualidade pode ocorrer com maior intensidade durante essa fase de transição.

A adolescente sofreu bullying ${ }^{1}$ durante muito tempo, em sua adolescência, sendo alvo dentro e fora de seu ambiente escolar. Estas agressões ocorreram de forma verbal, também existiram situações em que suas roupas foram roubadas no vestiário feminino enquanto ela tomava banho e uma outra situação vexatória quando bateram em sua bandeja de comida, fazendo que ela se sujasse no refeitório durante o horário de almoço, sendo exposta aos olhares críticos dos outros adolescentes. Nesse sentido, pode-se considerar que sua posição masoquista diante dos outros poderia alimentar o sadismo dos adolescentes que

\footnotetext{
${ }^{1}$ O termo Bulliyng de acordo com o dicionário Michaelis online: "Ato agressivo sistemático, envolvendo ameaça, intimidação ou coesão, praticado contra alguém, por um indivíduo ou um grupo de pessoas. Ocorre geralmente em escolas, porém pode ser praticado em qualquer outro local. Trata-se de ação verbal que pode, em situações extremas, evoluir para agressão física" (DICIONÁRIO, c2020).
} 
viviam maiores conflitos e tais situações concorriam para enfraquecer mais e mais a autoestima de Rachel.

Com relação ao comportamento de automutilação, é possível considerar que satisfaria também um desejo de punição, ou seja, a crença de que o ato de se lesionar justificaria suas ações para as outras pessoas, já que, possivelmente tenha internalizado, que estaria sempre destruindo coisas e pessoas. Agora seria ela a destruída.

Acerca da relação da personagem com seu corpo, pode-se também relacionar o ódio direcionado a ele com o conceito de corpo real, imaginário e simbólico desenvolvido, inicialmente, por Lacan (2018) no seminário 13 denominado "O objeto da psicanálise". Acerca do entendimento do autor, concordamos com o raciocínio de Victora (2016) que entende que ele evidenciou que o corpo real seria a composição orgânica do corpo, o corpo simbólico seria composto por uma junção de significados e pela linguagem e por fim, o corpo imaginário seria a forma como acredita-se ser visto pelas pessoas ou por si mesmo.

Para Victora (2016), este corpo biológico, real, sobrevive a partir da interferência de outras instâncias, como sentimentos, que surgem como simbologias, dando vida a esta forma corporal. No caso do corpo simbólico, a autora afirma que:

[...] vai se formando pela incorporação de significantes, desde as primeiras identificações. Trata-se mesmo de uma incorporação, ou da introdução, no corpo, de significantes dirigidos e/ou associados ao futuro sujeito - desde seu nascimento ou mesmo antes dele nascer - que vão criando um campo simbólico propício ao desenvolvimento de um sujeito (VICTORA, 2016, p. 2).

Quando se fala de corpo imaginário, é possível evidenciar que: "É a instância do imaginário que faz a costura do real com o simbólico. O único acesso possível ao corpo orgânico seria através do imaginário. Uma prova de que o corpo é imaginário são pessoas magérrimas que se acham gordas, bonitas que se acham feias, e vice-versa [...]" (VICTORA, 2016, p. 2).

A personagem apelidada Rae, mostra possuir um corpo simbólico repleto de sentimentos de inferioridade, que são internalizados na jovem a partir de suas relações sociais. A adolescente possui uma grande agressividade em relação a si mesma, fato que pode ser evidenciado com a prática de automutilação. Este corpo simbólico é formado por preconceitos e um grande medo de ser julgada pelos outros, fazendo com que ela crie um corpo imaginário formado apenas pela sua aparência física, não acreditando que possua outras características além do fato de ser gorda, um atributo de baixa valorização para ela. 
Com esta pesquisa pode-se evidenciar que o corpo, para a personagem, tornou-se palco do ódio que atribui a si mesma. Uma vez que durante o período da adolescência, o sujeito vive a morte do corpo infantil e entra em contato com um corpo adulto, usualmente desejante e desejado do prazer sexual genital em si mesmo e no outro, Rae parece demonstrar pela via do excesso de peso e ódio por esse corpo uma busca pela punição de seu desejo. Estas mudanças corporais vivenciadas geram um sofrimento profundo que Rae não consegue simbolizar, fazendo então com que ela desenvolva métodos de alívio para a dor que sente, por meio da repetição do ato de punição, causando feridas em seu próprio corpo. Esse corpo a representa por inteira, uma vez que, em seu entendimento, tudo o que ocorre é sofrido e estaria ligado com a maneira que ela e os outros enxergam sua forma corporal.

A série possibilita a reflexão sobre a forma como Rachel vivencia sua sexualidade, ligada diretamente com os sentimentos de vergonha e a culpa que ela atribui para si, fazendo então com que a jovem escolha se relacionar sempre de modo a esconder-se do olhar terrorífico que projeta nos outros, não conseguindo exercer, minimamente, sua sexualidade de forma livre. Recusa-se a perceber que alguém consiga achá-la atraente, buscando sempre evitar o contato com o outro.

Esta culpabilização sexual também pode estar interligada com a maneira com que ela vivencia seus hábitos alimentares, uma vez que há associação da alimentação com a sexualidade. Desta forma, assim como Rachel busca vivenciar, às escondidas, seus relacionamentos, também possui o comportamento de não conseguir comer na frente de outras pessoas, temendo a opinião alheia sobre sua forma de se alimentar.

A automutilação, no caso da personagem, surge com o intuito de confrontar as pulsões libidinais da jovem, que expressa seus conflitos e sofrimento por meio da dor em seu próprio corpo, que se torna o motivo de pertencimento na sociedade para ela, que se enxerga fora dos padrões sociais compartilhados pela comunidade e mídia, atribuindo assim uma grande repulsa e um grande sentimento de inferioridade pela sua figura.

\section{CONSIDERAÇÕES FINAIS}

Esta pesquisa teve como objetivo abordar o fenômeno da automutilação na adolescência, utilizando como embasamento teórico a psicanálise de base freudiana. Para 
ilustrar esse trabalho, optou-se por analisar a personagem central da série My Mad Fat Diary, devido ao fato desta ser uma adolescente que pratica ferimentos em seu próprio corpo.

A escolha por esta temática de estudo se deu a partir de uma necessidade pessoal em pesquisar sobre o comportamento autodestrutivo existente entre os adolescentes, buscando compreender os motivos que levam os mesmos a vivenciarem situações de risco e danos para si. Com estes questionamentos, surgiu a automutilação, que sempre existiu, porém atualmente tem ganhado maior visibilidade nas discussões clínicas e na mídia. Tratase de um problema de saúde pública, principalmente em relação aos jovens que cada vez mais reproduzem estas práticas, devido a diversos fatores psicológicos e sociais.

Este fenômeno pode ser cada vez mais visualizado nas escolas e nos consultórios, já que cada vez mais os adolescentes se encontram com dificuldades para lidar com seus sofrimentos psíquicos decorrentes das transformações físicas e psicossociais da adolescência. Porém, é necessário colocar que ser adolescente não significa ser um possível automutilador, porém, é durante este período que os jovens iniciam suas buscas por identificações, além de iniciarem o processo de construção de sua própria identidade. Com isso, é na adolescência que passamos a ser influenciados em todos os âmbitos de nossas vidas, seja por grupos sociais, familiares ou pelas mídias digitais, como a internet e as redes sociais, como já foram discutidas anteriormente nesta pesquisa.

A partir da realização desta pesquisa é possível considerar que existe uma necessidade geral em promover informações sobre a automutilação, sendo que devido à falta de conhecimento da sociedade sobre este comportamento, o sujeito que comete essa prática acaba por ser visto socialmente como alguém que deseja chamar atenção ou manipular as pessoas. Este olhar equivocado pode vir a gerar uma dificuldade no relacionamento entre pais e seus filhos praticantes de automutilação, pelo fato dos primeiros não conseguirem compreender o sofrimento dos jovens, negando e naturalizando os problemas deles. É de extrema importância que a automutilação seja abordada nos ambientes familiares e escolares, pois como sabemos, é uma questão muito vivenciada entre os adolescentes dos tempos atuais. A partir da promoção de uma maior informação sobre este assunto, as equipes escolares e as famílias podem pensar em novas estratégias de prevenção.

O psicólogo possui um papel extremamente importante na atuação com jovens que se automutilam, pois é este profissional que irá investigar e acompanhar este quadro, promovendo assim um espaço para que o sujeito, junto com o profissional, possa construir 
suas associações e interpretações em relação ao ato de se automutilar, buscando assim compreender a angústia profunda apresentada. Além disso, é fundamental que o psicólogo atue para fortalecer seu paciente, promovendo assim um ambiente onde ele se sinta acolhido, e possa falar de seu sofrimento de uma maneira livre, sem temer julgamentos ou acusações.

Por fim, esta pesquisa promoveu o conhecimento sobre a necessidade de um acompanhamento psicológico para os pais de sujeitos praticantes de automutilação, que, na maioria dos casos, relutam-se a aceitar os diagnósticos de seus filhos, mostrando-se irredutíveis em compreender os motivos que levam os jovens a se automutilarem. Este atendimento parental se torna também muito necessário devido ao fato, conforme apresentado anteriormente nesta pesquisa, dos pais serem as primeiras figuras de identificação de seus filhos, promovendo assim uma grande influência nas decisões e na forma como eles enxergam a si mesmos. Com isso, a família pode auxiliar o jovem a buscar uma ajuda especializada logo após a descoberta do quadro, para que este problema possa ser tratado de uma maneira precoce e eficiente, antes que chegue a um nível extremo.

\section{REFERÊNCIAS}

ABERASTURY, A.; KNOBEL, M. Adolescência normal: um enfoque psicanalítico. Porto Alegre: Artes Médicas, 1992.

ARAÚJO, J. F. B. de et al. O corpo na dor: automutilação, masoquismo e pulsão. Estilos da Clínica, São Paulo, v. 21, n. 2, p. 497-515, mai./ago. 2016. Disponível em: http://pepsic.bvsalud.org/pdf/estic/v21n2/a12v21n2.pdf. Acesso em: 27 out. 2020.

BRASIL. Lei $\mathbf{n}^{\circ}$. 8.069, de 13 de julho de 1990. Dispõe sobre o Estatuto da Criança e do Adolescente e dá outras providências. Brasília, DF: Presidência da República, 1990. Disponível em: http://www.planalto.gov.br/ccivil_03/leis//8069.htm. Acesso em: 27 out. 2020.

BRASIL. Lei $\mathbf{n}^{\circ}$. 13.819, de 26 de abril de 2019. Institui a Política Nacional de Prevenção da Automutilação e do Suicídio, a ser implementada pela União, em cooperação com os Estados, o Distrito Federal e os Municípios; e altera a Lei no 9.656, de 3 de junho de 1998. Brasília, DF: Presidência da República, 2019a. Disponível em: http://www.planalto.gov.br/ccivil_03/_Ato2019-2022/2019/Lei/L13819.htm. Acesso em: 28 out. 2020.

BRASIL. Ministério da Mulher, da Família e dos Direitos Humanos. O Suicídio e automutilação tratados sob a perspectiva da família e do sentido da vida. Brasília, DF: Ministério das Mulheres, da Família e dos Direitos Humanos, 2019b. 53 p. Disponível em: 
http://www.mpce.mp.br/wp-content/uploads/2019/01/20190104-Manual-de-estudos-dePreven\%C3\%A7\%C3\%A3o-do-Suicidio-MDHMC.pdf. Acesso em: 28 out. 2020.

CALLIGARIS, C. A adolescência. São Paulo: Publifolha, 2000.

CAMPBELL, D. NHS figures show 'shocking' rise in self-harm among young. The Guardian, Londres, 23 de outubro de 2016. Disponível em:

https://www.theguardian.com/society/2016/oct/23/nhs-figures-show-shocking-rise-selfharm-young-people. Acesso em: 27 out. 2020.

CENTRO LATINO-AMERICANO E DO CARIBE DE INFORMAÇÃO EM CIÊNCIAS DA SAÚDE. Descritores em Ciências da Saúde: DeCS. São Paulo: BIREME: OPAS: OMS, 2015. Disponível em: https://decs.bvsalud.org/. Acesso em: 10 mar. 2020.

DAVIS, N. Self-harm among girls aged 13 to 16 rose by $68 \%$ in three years, UK study finds. The Guardian: Londres, 8 de outubro de 2017. Disponível em: https://www.theguardian.com/society/2017/oct/18/self-harm-girls-aged-13-to-16-rose68pc-three-years. Acesso em: 26 out. 2020.

DICIONÁRIO Brasileiro da Língua Portuguesa. Michaelis, São Paulo, c2020. Disponível em: https://michaelis.uol.com.br/palavra/Vxme/bullying/. Acesso em: 28 out. 2020.

ERIKSON, E. H. Infância e sociedade. 2 ed. Rio de Janeiro: Zahar, 1976.

ESSLINGER, I.; KOVÁCS, M. J. Adolescência: Vida ou Morte. São Paulo: Ática, 1998.

FAVAZZA, A. Bodies Under Siege: self mutilation and body modification in culture and psychiatry. 2 ed. Baltimore: The Johns Hopkins University Press, 1996.

FREUD, S. Uma criança é espancada: uma contribuição ao estudo da origem das perversões sexuais. In: FREUD, S. Edição standard brasileira das obras psicológicas completas de Sigmund Freud. Rio de Janeiro, RJ: Imago, 1996a. v. 17, p. 193-218.

FREUD, S. Luto e melancolia. In: FREUD, S. Edição standard brasileira das obras psicológicas completas de Sigmund Freud. Rio de Janeiro, RJ: Imago, 1996b. v. 14, p. 243-266.

FREUD, S. O problema econômico do masoquismo. In: FREUD, S. Escritos sobre a psicologia do inconsciente. Rio de Janeiro, RJ: Imago, 1996c. v. 3, p. 103-124.

FREUD, S. Sobre o narcisismo: uma introdução. In: FREUD, S. Escritos sobre a psicologia do inconsciente. Rio de Janeiro, RJ: Imago, 1996d. v. 14, p. 133-173.

LACAN, J. 0 seminário, livro 13: o objeto da psicanálise. 2018. Edição não comercial destinada aos membros da Escola de Psicanálise dos Fóruns do Campo Lacaniano Brasil. Trabalho original publicado em 1965-1966. 
LAPLANCHE, J.; PONTALIS J. B. Vocabulário da Psicanálise. Tradução de Pedro Tamen. São Paulo: Martins Fontes, 2001.

LEVISKY, D. L. Adolescência: reflexões psicanalíticas. Porto Alegre: Artes Médicas, 1995.

LOURENÇO, B.; QUEIROZ, L. B. Crescimento e desenvolvimento puberal na adolescência. Revista de Medicina da USP, São Paulo, v. 89, n. 2, P. 70-75, abr./jun. 2010. Disponível em: https://www.revistas.usp.br/revistadc/article/view/46276. Acesso em: 27 out. 2020.

ORGANIZAÇÃO MUNDIAL DE SAÚDE. Classificação Estatística Internacional de Doenças e Problemas Relacionados à Saúde: CID-10. [S.I.]: Organização Mundial De Saúde, 2008.

PALACIOS, J. O que é a adolescência. In: COLL, C.; PALACIOS, J.; MARCHESI, A. (org.). Desenvolvimento psicológico e educação: psicologia evolutiva. Porto Alegre: Artes Médicas, 1995.

STRONG, M. A bright red scream: self mutilation and the language of pain. London: Penguin Books, 2009.

VENOSA, V. S. O "Ato de Cortar-se": uma investigação psicanalítica a partir do caso Amanda e do caso Catarina. 2015. Dissertação (Mestrado em Psicologia Social) - Instituto de Psicologia de São Paulo: Universidade de São Paulo, 2015. Disponível em: https://www.teses.usp.br/teses/disponiveis/47/47134/tde-19022016-153519/en.php. Acesso em: 27 out. 2020.

VERÍSSIMO, R. Desenvolvimento psicossocial (Erick Erickson). Porto: Faculdade de Medicina do Porto, 2002.

VICTORA, L. G. O corpo real, imaginário e simbólico. Porto Alegre: Associação Psicanalítica de Porto Alegre, 2016.

ZIMERMAN, D. E. Vocabulário Contemporâneo de Psicanálise. Porto Alegre: Artmed, 2001. 